\title{
Arte contemporânea e corporativismo: o colecionismo francês em debate
}

\author{
Henrique Grimaldi Figueredo \\ DOI 10.20396/eha.vil4.3353
}

Introdução: critérios de consagração e o papel contemporâneo do colecionismo O sociólogo francês Alain Quemin situa a gênese do que hoje é compreendido por 'arte contemporânea' em ocasião da mostra When Attitudes Become Form - curadoria de Herald Szeeman - em Berna (Suíça), em 1969. Curiosamente e não sem razão, data deste mesmo momento, mais especificamente de 1970, a publicação da primeira lista KunstKompass, uma espécie de bússola dessa nova arte que classificava e organizava os cem artistas vivos mais importantes do mundo².

A KunstKompass foi publicada quase anualmente de 1970 a 2008, primeiramente sob a égide de seu criador, o jornalista alemão especializado na área econômica Willy Bongard, e posteriormente por sua viúva Linde Rohr-Bongard. Criticada em inúmeras ocasiões por sua suposta incontestabilidade, a KunstKompass apenas perde seu protagonismo em 2008 quando a revista Capital em parceria com a equipe da Artfatcs passa a publicar a Capital KunstmarktKompass, que apresentava o mesmo objetivo mas partia de um conjunto de critérios e avaliações cuidadosamente mais integralistas. Diferente do primeiro esforço de mensurabilidade da consagração artística da KunstKompass (que considerava as exposições individuais a partir da importância das instituições e espaços em que eram realizadas; as exposições coletivas e em bienais; e as publicações em periódicos especializados de renome internacional como Art in America e Artforum), os critérios operacionais da Capital KunstmarktKompass passam a contabilizar processos outros de modo a proporcionar um retrato acertadamente mais realista da arte em seu meio social.

A Artfacts utiliza uma gama muito maior de instâncias qualificadoras: galerias de arte contemporânea, instituições públicas (que possuam ou não a sua própria coleção, sejam museus ou centros de arte), bienais e trienais, outros espaços de exposições temporárias, feiras de arte contemporânea, leilões, art hôtels, revistas, jornais e magazines de arte, livros de arte, escolas de arte, festivais, organizações sem fins lucrativos, instituições de gestão artística ou coleções particulares ${ }^{3}$.

\footnotetext{
1 Doutorando em Sociologia pelo Instituto de Filosofia e Ciências Humanas da Universidade Estadual de Campinas - UNICAMP. Agência financiadora: Fundação de Amparo à Pesquisa do Estado de São Paulo - FAPESP.

2 QUEMIN, 2016.

3 QUEMIN, 2016, s/p.
} 
Pois bem, simultaneamente e paralelamente à essa presumida hegemonia, sabemos que o campo artístico encontra-se em perpétua concorrência. Se para Bourdieu ${ }^{4}$ campo existe na/a partir de suas disputas internas, a emergência de novas listas e critérios de avaliação da consagração artística habitam exatamente esse jogo discursivo onde capitais são negociados e acumulados por seus agentes, cada um deles objetivando os aspectos de dominação (aspectos subordinantes que só existem condicionados aos elementos que lhe são subordinados) de vocalização do que a arte é, e quais são os seus atores de maior relevância.

É nesse sentido que outras categorizações são produzidas, assim como novas listas que levam em consideração aspectos cada vez mais complexos do campo artístico, deslocando a centralidade da produção (artistas) para suas operações de mediação e recepção. A dimensão plástica e teórica das artes, outrora substancialmente importantes, são agora perturbadas por uma redistribuição cada vez mais vigorosa das instâncias de legitimação do campo artístico. A globalização dos mercados e a financeirização da cultura, nomeadamente a partir dos anos 1980, fornecem novo peso à agentes antes secundários nesse campo.

Se considerarmos, por exemplo, a lista Power1oo da revista inglesa ArtReview, perceberemos uma alteração considerável em sua metodologia: não mais restringe-se a definição dos artistas mais importantes, mas sim dos cem agentes mais relevantes de todo campo artístico, interseccionando para esse fim vinte gêneros de atuação, origens geográficas e os anos em que esses agentes são mais relevantes ${ }^{5}$. Esse novo modelo reconhece, portanto, as dimensões dos mercados, das instituições e da produção de discursos sobre arte, reequilibrando seus poderes na definição das legitimidade do campo artístico.

Analisando os dados da lista Power100 - de 2002 a 2018 - a partir das categorias "colecionador" e "galeristas", seccionadas pela nacionalidade - "franceses" - podemos tecer algumas considerações (Ver Gráfico 01). Na primeira destas categorias a porcentagem varia de 1 a 3\% entre os anos pesquisados, sendo $2 \%$ o dado de maior frequência. Ao cruzarmos esse grupo com os galeristas, percebemos uma variação de maior envergadura, isto é, de $2 \%$ em 2002 à 6\% em 2016, e 5\% em 2018. De imediato esses números aparentam certa desimportância, entretanto se consideramos

\footnotetext{
4 BOURDIEU, 1996.

5 As vinte categorias elencadas pela lista Power1oo da ArtReview são: Adviser; Architect; Art Fair; Art Fair Director; Art School Director; Artist; Auction House; Auction House Director; Collector; Curator; Director; Foundation Funder; Foundation Funder-Curator; Gallerist; Museum Director; Museum Director-Curator; Philosopher; School Director; Website; Writer. Essa leitura torna-se relativamente mais complexa e poderia ser interpretada, por exemplo, a partir da ótica das teorias ANT (actor-network-theory) do sociólogo francês Bruno Latour em sua noção de agências não-humanas (aqui representadas pelas modalidades Art Fair, Auction House e Website) (FICUEREDO, ALMEIDA, 2018). Fonte: https://artreview.com/power_100/.
} 


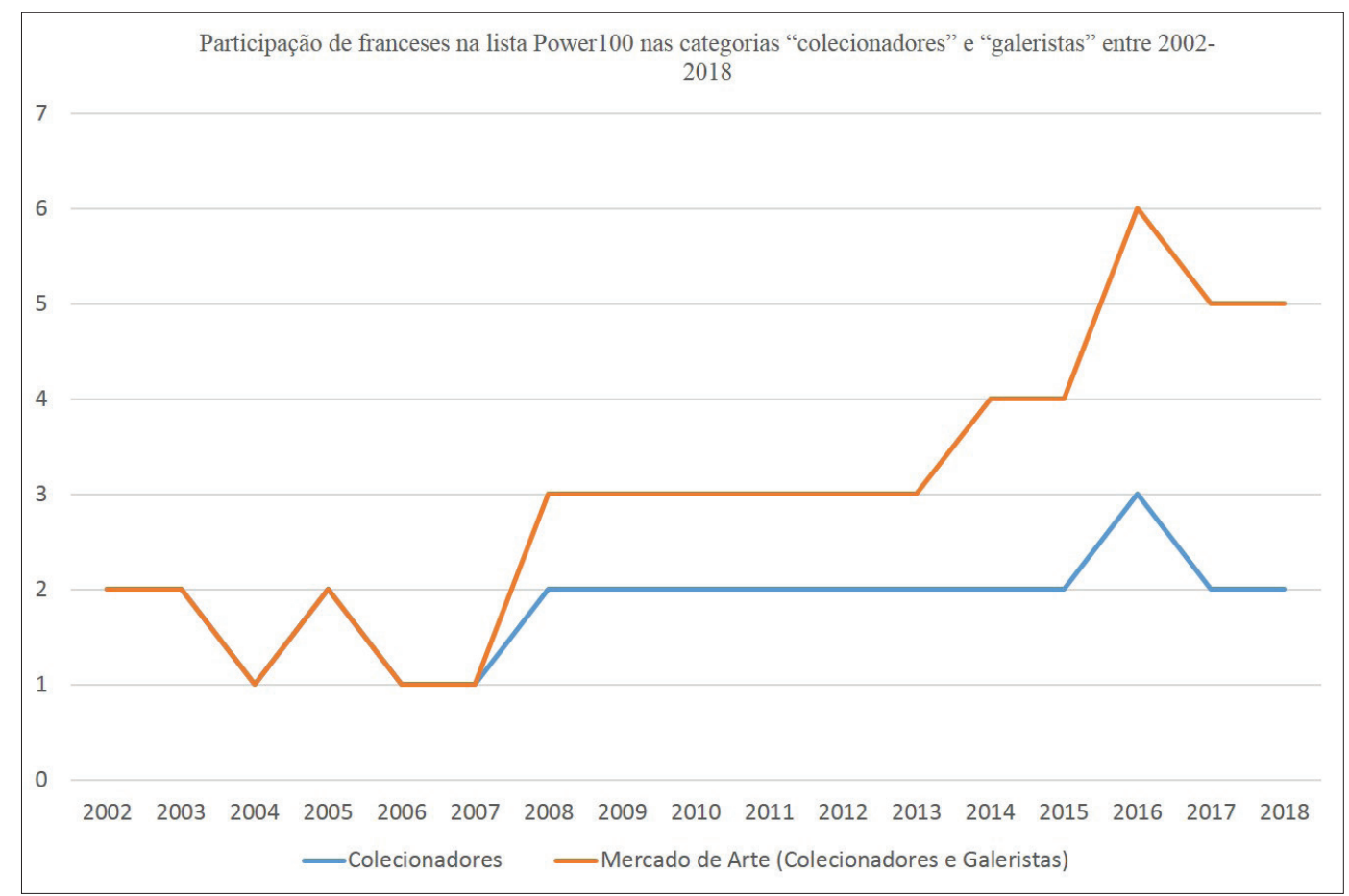

[Gráfico 01] Participação de franceses na lista Powernoo nas categorias "colecionadores" e "galeristas" entre 2002-2018.

Autoria própria.

que a nível global e apenas na seção "mercado de arte e colecionismo" os agentes de origem francesa equivalem à $6 \%$ de sua totalidade, há evidentemente um peso político e econômico substancial desses sujeitos nos processos de dominação do campo artístico.

Se o mercado de arte - o francês em específico - assume um peso avultado nessa análise, é porque algumas alterações consideráveis vem ocorrendo nas últimas décadas. Cabe-nos aqui os questionamentos: Qual o papel do mercado nas definições e discursos sobre a consagração artística? Quais mudanças podemos identificar como sendo cruciais à essa redistribuição dos capitais na contemporaneidade e quais as suas consequências?

\section{Colecionismo francês em debate}

Em uma leitura mais atenta dos dados recolhidos, um fato nos chama a atenção pela sua regularidade. Na categoria "colecionador" da Powernoo dois nomes assumem certa preponderância desde a primeira publicação da lista em 2002. De fato, outros agentes atuantes no mercado e no colecionismo adentram a lista apenas a partir de 2008. A constância em que François Pinault (presente em todas as versões da lista de 2002 a 2018, e sendo em 2004 a terceira pessoa mais influente 
do mundo da arte, e em 2006 e 2007, o agente de maior influência, estando em $1^{\circ}$ lugar em ambas) e Bernard Arnault (curiosamente ausente nas listas de 2004, 2006 e 2007, mas presente em todos os demais anos) surgem nessa contabilização é no mínimo sintomática ${ }^{6}$. Ela denota uma alteração na disposição dos humores e do funcionamento no universo artístico.

Para Nathalie Moureau e Dominique Sagot-Duvauroux estamos lidando com um outro tipo de colecionadores - não mais milionários, mas bilionários - que garantem pelo acúmulo de capitais - econômico e social, transmutados posteriormente em capitais simbólicos e artísticos - seu lugar como unidade legítima - com alcance global - na criação de padrões de sociabilização e culturalização que atingem não só os participantes deste universo (novas gerações de artistas, curadores, críticos) mas também "gotejam" em outros nichos da sociedade, subordinando-as e alterando em parte o que percebemos como arte ${ }^{7}$.

Atualmente os discursos sobre o mercado de arte tornaram-se indissociáveis de temas como os processos de globalização dos mercados, a formatação de uma cultura mundializada e, sobretudo, do redesenho das dinâmicas do capitalismo como sistema de produção e consumo cultural. Debate situado no início dos anos 1980, os processos de formação de mercados globais fundamentam uma redistribuição de poder político culminando numa progressiva transferência da cultura antes gerenciada majoritariamente pelo Estado - ao capital empresarial, num movimento descrito por Chin-Tao Wu (2006) como "privatização da cultura". Ao ser privatizada, a cultura, e as artes em seu seio, também passam por significativas alterações: o colecionismo pode ser eclipsado por dinâmicas empresariais, e o gosto - categoricamente intransferível e pessoal - torna-se, muitas vezes, corporativamente construído e economicamente interessado ${ }^{8}$.

Movimento compartilhado por diversas nações ocidentais, na França "os ministérios da Cultura sucessivos desenvolveram mecanismos legislativos e regulamentares de retomada do mercado e de incentivo à iniciativa de pessoas físicas e de empresas" ${ }^{\prime 9}$. Esse processo promoveu um movimento dúbio: se por um lado auxilia na formalização do setor e no reconhecimento de seus agentes, por outro, permite a entrada abrupta da iniciativa privada no setor cultural culminando com o nascimento de fundações e museus impulsionados por novos colecionadores, cuja motivação -

\footnotetext{
6 Bernard Arnault e François Pinault são empresários franceses do ramo do luxo e da moda. Ambos possuem museus que abrigam suas coleções de arte (Fondation Louis Vuitton e Collection Pinault, respectivamente) e participam do mercado através de ativos investidos em casas de leilão como a Christie's, Phillips e SVV Tajan (MOULIN, 2007).

7 MOUREAU, SACOT-DUVAROUX, 2016.

8 FICUEREDO, 2019.

9 MOULIN, 2007, p. 88.
} 
categoria fundamental na pesquisa sobre colecionismo - cambia-se, vez ou outra, em especulação ${ }^{10}$.

Os estímulos financeiros e os abatimentos tributários oriundos da compra de arte deram origem a uma outra tipologia de investidor na cena artística, deslocando o apelo subjetivo da produção artística ao quadro do lucro e da liquidez de ativos, isto é, da emergência de um colecionismo corporativo muitas vezes estrategicamente elaborado. Na França esse quadro é particularmente complexo e está associado à

Abertura do mercado de arte em 2001 - e as leis de regulamentação do setor de 4 de julho e de 17 de dezembro de $2002^{11}$ - possibilitaram que indústrias com alto poder econômico (conglomerados da moda,) se aventurassem no mercado internacional, o que explica a aquisição de casas de leilão anglo-saxônicas (Christie's e Phillips) pelo capital francês (Kering - François Pinault - e LVMH - Bernard Arnault - respectivamente) ${ }^{12} 13$.

Funcionando a partir de uma lógica específica - que contabiliza por exemplo as hype informations e a produção de pequenos eventos históricos ${ }^{14}$ - essa modalidade de colecionismo que concentra capitais nas mãos de alguns poucos agentes deve ser problematizada no sentido de uma elaboração artificial de carreiras e tendências estéticas contemporâneas. Raymonde Moulin ao estudar os padrões de consagração artística na França, identifica igualmente a centralidade que determinados colecionadores assumem na elaboração de discursos e práticas na arte contemporânea. Para a socióloga, esses megacolecionadores

Exercem um poder de mercado: compram um grande número de obras, entre as quais várias do mesmo artista, a um preço relativamente baixo e, em acordo com o ou os marchands promotores do artista, controlam a oferta. Trata-se ai de uma colusão não habitual entre compradores e vendedores, para restringir a oferta e elevar os preços, (...), a entrada em uma grande coleção tem um efeito muito positivo na reputação do artista. Além do mais, a participação dos megacolecionadores nos conselhos de administração dos grandes museus garante a presença dos artistas que mantêm nas instituições culturais, (...), Eles tem, com efeito, o cuidado constante de não desvalorizar os artistas dos quais possuem obras, as quais constituirão, se for o caso, o fundo de um museu com o seu nome. Ao mesmo tempo ator cultural e ator econômico, o megacolecionador desempenha alternativamente

\footnotetext{
10 FIGUEREDO, 2019.

11 A lei de 4 de julho de 2002 instituiu a dedução fiscal para doações de obras adquiridas por empresas a museus. Já a lei de 17 de dezembro de 2002 definiu os novos formatos do mecenato e criou ferramentas de estímulo a consolidação de coleções e fundações privadas abertas ao público (MOULIN, 2007; BUENO, 2016).

12 Bernard Arnault e François Pinault são empresários franceses do ramo do luxo e da moda. Ambos possuem museus que abrigam suas coleções de arte e participam do mercado através de ativos investidos em casas de leilão (MOULIN, 2007).

13 FIGUEREDO, 2019, pp. 4-5.

14 Sobre isso, consultar MOUREAU, Nathalie; SAGOT-DUVAUROUX, Dominique; VIDAL, Marion. Collectiounners d'art contemporain. Paris: Ministère de la Culture, 2016.
} 
todos os papéis, o de marchand (ele compra e, eventualmente, revende), de curador, de mecenas (doações e fundações) ${ }^{15}$.

Não há, portanto, uma mera redistribuição de valores e papéis na definição do campo artístico, mas uma justaposição, isto é, determinados agentes concentrando um grande número de poderes que os habilitam a participar da produção da crença - nos termos bourdieusianos - do que pode ser compreendido, apreciado e valorizado como arte na contemporaneidade. Tornam-se assim agentes híbridos, atores culturais-econômicos que exercem muito poder na produção e legitimação da arte posto que a um só tempo operam na definição da oferta artística, mas também formando e informando a demanda, da qual eles próprios constituem um segmento dominante, a saber, subordinantes de outros sujeitos e práticas pelo conjunto de relações sociais e capitais acumulados.

Evidentemente, não queremos dizer com isso que colecionadores "bem intencionados" e que adquirem arte por razões subjetivamente complexas tenham desaparecido, nem que os dois colecionadores supracitados estejam engajados em processos puramente especulativos, e tampouco que as dinâmicas, disputas e discursos tradicionais ao campo artístico tenham desaparecido. O que descrevemos aqui é uma dimensão outra que apenas complexifica nossa compreensão das praxes envolvidas na produção, mediação e circulação da arte contemporânea. O que tentamos pontuar é que uma análise dos objetos, sujeitos e práticas artísticas que desconsidere os poderes e papéis exercidos pelos colecionadores e pelo mercado será sempre perspectivada e lacunar. O que desejamos pontuar é que as relações entre os mundos da produção artística e de sua recepção e mediação são indissociáveis das operações mercadológicas e dos processos artificialmente e socialmente elaborados de consagração: olhar para a arte sem considerar os seus mercados seria, no mínimo, incauto.

Pois bem, se a regularidade de agentes como Bernard Arnault e François Pinault em listas recentes sobre o universo artístico nos diz algo é que devemos ponderar os elementos de privatização e financeirização da cultura como substanciais para pensarmos as atividades artísticas na contemporaneidade. François Pinault, por exemplo, figura nos últimos anos como o maior colecionador de arte contemporânea do mundo. Sua coleção possui mais de 3500 peças e distribui-se por espaços de exposição em Paris (Bourse de Commerce) e em Veneza (Punta dela Dogana; Pallazzo Grassi; Teatrino); é também acionista majoritário da casa de leilões anglo-saxônica Christie’s, a segunda

15 MOULIN, 2007, pp. 28-29. 
em volume de vendas de arte contemporânea ${ }^{16}$.

A participação de colecionadores da envergadura de François Pinault e Bernard Arnault no universo artístico culmina no remonte do conjunto de relações entre as diferentes instâncias de sua sagração - a saber, artistas, marchands, curadores, críticos, galerias, museus, etc - produzindo, em consequência, algumas ameaças à formalização tradicional do campo. Assim, a participação de grandes colecionadores no mercado - não apenas como compradores, mas acionistas de casas de leilão - e nos conselhos museísticos podem acarretar: (a) a elaboração das informações artísticas através de seus museus privados e dos empréstimos de obras para exibição a coleções nacionais; (b) o fim das diferenças entre preço e valor, o que pode produzir bolhas especulativas no mercado uma vez que os critérios de valoração da arte passam agora por outras instâncias (devemos considerar as hype informations nessa matemática simbólica); (c) um jogo de mercado que cria artificialmente as hype informations ${ }^{17}$ e pode encetar processos igualmente artificiais de artificação ${ }^{18}$; (d) museus públicos, muitas vezes atrelados a baixos orçamentos, tonando-se dependentes dos colecionadores para empréstimo de obras importantes e patrocínio de exposições e (e) a produção da crença em determinadas práticas que são convalidadas artificialmente pela estreita relação entre o capital privado e as instituições públicas que dele dependem num jogo de simbiose coparticipativa e muitas vezes interessada.

Portanto, a hipótese aqui levantada - e sustentada por investigações da sociologia da arte sobre a relação entre arte e capital econômico ${ }^{19}$ - compreende que as corporações atuantes no mercado de arte estruturam-se como oligopólios de franja nos quais poucas empresas assumem certa notoriedade. Essa estrutura não acarreta o desaparecimento de outros negócios que executam as mesmas ou funções aproximadas, mas produz um protagonismo de umas em detrimento de outras.

16 QUEMIN, 2014; ALVAREZ, 2018; FIGUEREDO, 2019.

17 As hype informations, para Moureau e Sagot-Duvauroux (2016), correspondem àquele conjunto de informações espetacularizadas sobre a obra de arte - como recordes em vendas de leilão - que não correspondem efetivamente ao valor artístico da obra. Nesse sentido, ao estudarmos a arte contemporânea devemos ter sempre em mente as diferenças fundamentais entre valor e preço, esse segundo variando artificialmente por uma série de operações interessadas das quais as hype informations fazem parte.

18 A artificação para as sociólogas francesas Roberta Shapiro e Nathalie Hienich é a transformação da não-arte em arte (SHAPIRO, HEINICH 2013). Pode ser compreendida como um processo de processos que requalificam simbolicamente determinadas práticas e objetos. Nossa hipótese é de que, sendo um processo socialmente elaborado - e portanto artificialmente construído - estes colecionadores com suas instituições e museus, mas também seu alto volume de capital acumulado e influência sobre instituições públicas, estariam apto a promoverem procedimentos interessados de artificação, transformando práticas e elementos específicos em arte e visando - como mostra Moulin (2007) - nunca desvalorizarem suas coleções privadas. Essas dinâmicas por sua vez alterariam de modo mais ou menos geral, o que é promovido e compreendido como arte à nível global (FICUEREDO, 2019).

19 MOULIN, 2007; MOULIN, 1992; WU, 2006; BUENO, 2016. 


\section{Pistas conclusivas}

Se observarmos as categorias estabelecidas por Howard Becker ${ }^{20}$ em seus Mundos da Arte - criação, mediação e recepção - identificamos um possível reordenamento em seus pesos quando colididos com o colecionismo contemporâneo. Práticas relativas à mediação e à recepção dos trabalhos e dos artistas - devido ao acúmulo de capitais pelos colecionadores e instituições privadas podem encetar ou barrar carreiras, dispositivos e determinadas estéticas. A nossa hipótese - apenas uma das muitas leituras possíveis - atua no diagnóstico dos procedimento de mediação e institucionalização das obras como muitas vezes superlativo aos métodos de criação. Conclusivamente, a compreensão da arte e de suas dinâmicas na contemporaneidade é indissociável de sua relação com o mercado e o colecionismo. Somente a partir desta chave complexa que equaciona essas diferentes dimensões é que podemos compreender os caminhos das visualidades contemporâneas e da arte como prática social. 


\section{Referências Bibliográficas}

ALVAREZ, José. François Pinault, artiste contemporain. Paris: Albin Michel Editions, 2018.

BECKER, Howard. Art Worlds. Berkeley: University of California Press, 1982.

BOURDIEU, Pierre. As Regras da Arte: Cênese e Estrutura do Campo Literário. São Paulo: Cia das Letras, 1996.

BUENO, Maria Lucia. La condition d'artiste contemporain: entre l'université et le marché. In: Art et Societé (Org. A. Quemin e G. Villas-Boas), Marseille, Open Edition Press, 2016.

FICUEREDO, Henrique Grimaldi. It's not you, its your prices at auction: arte e mercado em Pablo Helguera. Revista do Centro de Pesquisa e Formação do SESC-SP, nº 9, 2019.

FIGUEREDO, Henrique Grimaldi; ALMEIDA, Thamara Venâncio de. Diálogos sociotécnicos e existências híbridas: a abordagem de Bruno Latour aplicada à performação na passarela de Alexander McQueen. CES REVISTA, v. 32, nº 2, 2018.

MOULIN, Raymonde. O Mercado da Arte: mundialização e novas tecnologias. Porto Alegre: Zouk, 2007

MOULIN, Raymonde. L'Artiste, l'instituition et le marché. Paris: Flammarion, 1992.

MOUREAU, Nathalie; SACOT-DUVAUROUX, Dominique. Le marche de l'art contemporain. Paris: La Découverte, 2016.

MOUREAU, Nathalie; SACOT-DUVAUROUX, Dominique; VIDAL, Marion. Collectiounners d'art contemporain. Paris: Ministère de la Culture, 2016.

QUEMIN, Alain et al. O valor da obra de Arte. São Paulo: Metalivros, 2014.

QUEMIN, Alain. A distribuição desigual do sucesso em arte contemporânea entre as nações: uma análise sociológica da lista dos 'maiores' artistas do mundo. In: QUEMIN, Alain; VILLAS-BÔAS, Claucia. Arte e vida social. Paris: Open Edition Press, 2016.

SHAPIRO, Roberta; HEINICH, Nathalie. Quando há artificação? Sociedade e Estado, Brasília, v.28, n.1, jan/abr., 2013.

WU, Chin-Tao. A privatização da cultura. A intervenção corporativa nas artes desde os anos 1980. São Paulo: SESC/Boitempo, 2006. 